\title{
Effects of the Mass Transfer Process in Oil Spill
}

\author{
Fabián Betancourt, Arturo Palacio and Alejandro Rodriguez \\ Coordinación de Ingeniería de Procesos Industriales y Ambientales del Instituto de Ingeniería de la \\ Universidad Nacional Autónoma de México, 04510, Coyoacan, México, D.F., México
}

\begin{abstract}
A revision of the models used to study the behavior of the mass loss processes associated with petroleum spills on water and to compare those models with experimental data. The processes of mass transfer studied in this work are evaporating, dissolution, vertical dispersion, emulsification and the changes of properties associated with these. The comparison of the estimations with the field data allowed determining the utility and the degree of adjustment of the expressions.
\end{abstract}

Key words: Oil Spill, Mass Transfer Process, Models, Evaporation, Dissolution, Vertical Dispersion

\section{INTRODUCTION}

A petroleum spill on a water body is normally divided in several slicks, while that is dissipated by the natural process. The dissipation is the sum of the physical, chemical and biological processes that act on the spill changing their extension and composition. The dissipation could be divided in two parts: biodegradation (biological processes) and motorization (physical and chemical processes).

The action of the physical, chemical and biological processes depend of the type of the petroleum spilled (products as the kerosene evaporates quickly and it does not require cleaning, whereas the paraffin base dissipates slowly, requiring cleaning). The physical properties like density, viscosity and point of evaporation determine the behavior of the spill (Fig. 1).

The evaporation, the vertical dispersion, the emulsification and the dissolution are the most important processes in the first hours of the spill. The meteorological (wind, solar radiation and temperature, etc.) and hydrodynamic (waves, currents and tides) conditions together with the characteristics where the spill occur must be considered in the study of the mass loss processes.

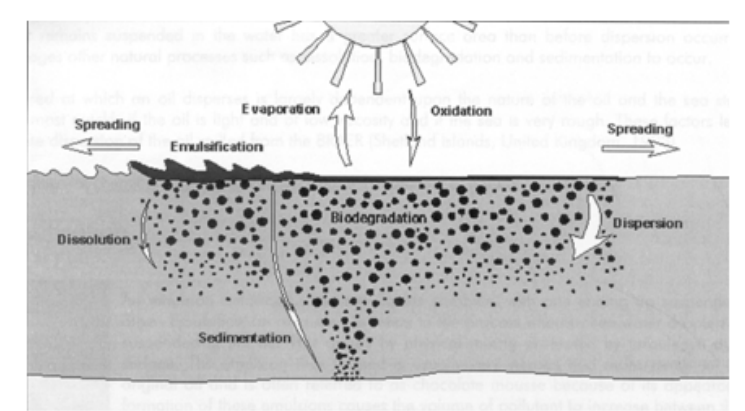

Fig. 1: Physical, Chemical and Biological Process in Oil Spills
In general, the models of mass transport are classified in two groups: the pseudo components and analytical models. The differences are in the type of information required; whereas for the pseudo component models the composition and properties are required, the analytical models consider that each petroleum is a single component. The pseudo component model results can be better that the analytical models, if you have with the petroleum characterization.

Evaporation: Evaporation is the most important mass loss process in a petroleum spill. For example: a light petroleum can be evaporated up to $75 \%$, a medium up to $40 \%$ and a heaving up to $10 \%$, in the first days; for that reason, it is included in the most models.

\section{Pseudo component Models:}

Model of Stiver and Mackay ${ }^{[1]}$ : This model is a modification work of Mackay and Matsugy ${ }^{[2]}$. It is based on the mass transport coefficient expression obtained from experimental data. This model proposes to find the fraction of the evaporated petroleum through the experimental constants, thus:

$\frac{d f}{d t}=\frac{K e}{h} \exp \left[K_{1}+K_{2}\left(C_{1}+C_{2} F\right)\right]$

where $K_{1}=48.5-0.1147 T_{o}, \quad K_{2}=4.5 * 10^{-4} T_{o}-0.1921$, $K_{e}=2.5 * 10^{-3} U_{0}^{0.78}, T_{0}$ is the environmental temperature in ${ }^{\circ} \mathrm{K}, \mathrm{h}$ is the thickness of the slick in $\mathrm{m}, \mathrm{C}_{1}$ and $\mathrm{C}_{2}$ are the experimental data obtained by oil distillation and $\mathrm{F}$ is the evaporation fraction.

Model of Reed et al.$^{[3]}$ : In this model, the mass transfer of oil to environmental is calculated for each component, thus:

$\frac{d m_{i}}{d t}=\frac{K_{B} P_{v_{i}} A f_{i} M_{i}}{R T}$ 
where, $\mathrm{dm}_{\mathrm{i}}$ is the mass transfer for each component in gr, dt is the time in the $\mathrm{s}, \mathrm{K}_{\mathrm{B}}$ the transfer coefficient, $\mathrm{P}_{\mathrm{Vi}}$ the vapor pressure of each component in ATM, A is the slick area in $\mathrm{m}^{2}, f_{i}$ the remaining fraction of each component, $\mathrm{M}_{\mathrm{i}}$ the molecular weight of each component in $\mathrm{g} \mathrm{mol}^{-1}, \mathrm{R}$ is the universal constant of gases equal to $8.206^{*} 10^{-5}$ in $\mathrm{ATM}^{-\mathrm{m}^{3}} \mathrm{~mol}^{-1}{ }^{\circ} \mathrm{K}$, and $\mathrm{T}$ is the temperature of water surface in ${ }^{\circ} \mathrm{K}$. It is possible that the temperature of the air near the surface of the spill will be used but the temperature spill is always preferred.

The following function ${ }^{[4]}$ is used for calculating $\mathrm{K}_{\mathrm{B}}$, thus:

$K_{B}=0.029 U_{10}^{0.78} D^{-0.11} S c^{-0.67} \frac{\sqrt{M_{i}+29}}{M_{i}}$

where, $U$ is the wind velocity of $10 \mathrm{~m}$ overseas in $\mathrm{m}$ $\mathrm{h}^{-1}, \mathrm{D}$ is the slick diameter and $\mathrm{S}_{\mathrm{c}}$ is the Schmidt number equal to 2.7 .

Model of Shen and Yapa ${ }^{[5]}$ : This model uses an improved expression (11) that permits to calculate the fraction of loss mass:

$$
\begin{aligned}
& F=\left(\frac{1}{C}\right)\left[\ln P_{0}+\ln \left(C K_{E} t+\frac{1}{P_{0}}\right)\right] \\
& C=1158.9 A P I^{-1.1435} \\
& K_{E}=\frac{0.0025 U^{0.7} A v}{R T V_{0}} \\
& v=\frac{P M}{\rho \times 10^{-6}}
\end{aligned}
$$

$-0.03439 A P I^{3}+0.0002604 A P I^{4}$

$$
A P I=\frac{141.5-131.5 s \cdot g \cdot 60^{\circ} \mathrm{F}}{s . g \cdot 60^{\circ} \mathrm{F}}
$$

where, $\mathrm{C}$ is an evaporation constant, $\mathrm{K}_{\mathrm{E}}$ is the exponent of evaporation, $t$ is the time in the $s, U_{10}$ is the wind speed in $\mathrm{m} \mathrm{s}^{-1}$ measured at $10 \mathrm{~m}$ over the sea level, $\mathrm{A}$ is the area of the petroleum spill in $\mathrm{m}^{2}, \mathrm{~V}_{0}$ is the molar volume in $\mathrm{m}^{3} \mathrm{~mol}^{-1}, P M$ is the petroleum molecular weighting $\mathrm{mol}^{-1}, \rho$ is the density of petroleum in $\mathrm{g}$ $\mathrm{cm}^{-3}, \mathrm{R}$ is the universal constant of gases equal to $8.206 * 10-5$ in $\mathrm{ATM}-\mathrm{m}^{3} \mathrm{~mol}^{-1}{ }^{\circ} \mathrm{K}, \mathrm{T}$ or $\mathrm{T}_{\mathrm{E}}$ is the temperature of the surface in ${ }^{\circ} \mathrm{K}, \mathrm{V}_{0}$ is the spilled initial volume in $\mathrm{m}^{3}, \mathrm{P}_{0}$ is the initial vapor pressure in the ATM at $T_{E}, T_{0}$ is the reference temperature, API is API gravity, and s.g. is the petroleum specific gravity at $60^{\circ} \mathrm{F}$.

Model of Findicakis $\boldsymbol{e t}$ al. ${ }^{[6]}$ : It uses a simplified model in which the evaporation coefficient for each component is constant. In this model the evaporation is the function of the vapor pressure and the wind speed. This expression is also a modification of the model of Hackay et al. ${ }^{[4]}$ :

$\phi_{i}=\lambda_{i}\left(P_{v i}-P_{v a i}\right) U$

where, $\phi_{i}$ is the rate of evaporation for each component in $\mathrm{g} \mathrm{cm}^{-3}-\mathrm{s}, \lambda_{i}$ is the evaporation coefficient for each component equal about $10^{-12}$ in $1 / \mathrm{cm}^{3}$ and it can be considered constant, $\mathrm{P}_{\mathrm{vi}}$ the vapor pressure of each component in dyn $\mathrm{cm}^{-2}, \mathrm{P}_{\text {vai }}$ the vapor pressure of each component in the air over the sea, which is generally zero and $U$ is the wind velocity at 10 $\mathrm{m}$ over the sea in $\mathrm{cm} \mathrm{s}^{-1}$.

Analytical Model:

Model of Fingas ${ }^{[7,8]}$ : It suggests that the evaporation can be calculated as a function of the time, the temperature and the mass evaporated percentage to $180^{\circ} \mathrm{C}$, for this reason this expression requires a laboratory previous test. Oil groups with the quadratic and logarithmic behavior were found, for that reason, the following expressions were formulated:

Logarithmic Form:

$\% E=[0.165 \times \% D+0.045(T-15)] \ln t$

Quadratic Form:

$\% E=[0.0254 \times \% D+0.01(T-15)] \sqrt{t}$

where, $\% \mathrm{E}$ is the evaporated mass percent, $\% \mathrm{D}$ is the evaporated mass percent at $180{ }^{\circ} \mathrm{C}$, $\mathrm{T}$ is the temperature in ${ }^{\circ} \mathrm{C}$ and $\mathrm{t}$ is the time in min.

This model is well documented since it is possible to find the characterization of many oils from the Center for Environmental Technology of Canada (www.etcentre.org), from the simplified correlation, thus:

$\% E=(A+B T) \ln t$

where, $\mathrm{A}$ and $\mathrm{B}$ are experimental dates.

Dissolution and Vertical Dispersion: The dissolution usually only represents up to $1 \%$ of the loss mass, but 
the dissolved products can be important their toxic effects, for that reason sometimes the detailed description of petroleum is required.

The vertical dispersion increases the superficial transfer area, favoring the dissolution, the biodegradation and the sedimentation. The turbulence determines the diameter and the distribution of the suspended drops. The characteristics of the petroleum (the viscosity, the superficial tension and the light components), the waves and the speed of the dispersion determine the amount of the dispersed petroleum. Sometimes, the addition of the chemical dispersing favors the dispersion ${ }^{[9]}$.

The dissolved oils that come from the dispersed drops in water could represent a similar percentage to the dissolved in direct form. There are not algorithms that represent this phenomenon ${ }^{[10]}$.

The most soluble compounds in water are the light aromatic like the benzene and the toluene; nevertheless, these are also the first to evaporate. Comparatively, the evaporation is 10 to 100 times faster than the dissolution, for this reason, the dissolution is quantitatively not important ${ }^{[4]}$.

Model of Dissolution of Cohen et al.. ${ }^{[10]}$ : They proposed that the dissolution could be estimated as a function of the superficial area of slick:

$$
\frac{d m}{d t}=K A_{s} C_{0} e^{-\alpha t}
$$

where, $\mathrm{K}$ is the transfer mass coefficient in $\mathrm{m} \mathrm{h}^{-1}, \mathrm{~A}_{\mathrm{s}}$ is the superficial area of slick in $\mathrm{m}^{2}, \mathrm{C}_{\mathrm{o}}$ is the oil solubility in fresh watering $\mathrm{m}^{-3}, \propto$ the decay exponent in dye $\mathrm{e}^{-1}$ and $\mathrm{t}$ is the time in $\mathrm{hr}$. The following values for $\mathrm{K}, \mathrm{C}_{\mathrm{o}}$ and $\propto$, were found ${ }^{[5]}$.

Vertical Dispersion Models: In general, any of the models that follow can be used, according to information availability.

Model of Mackay et al., ${ }^{[11]}$ : They proposed that the oil mass transferred for vertical dispersion could be calculated:

$\frac{d m}{d t}=\frac{0.11 m(1+U)^{2}}{1+50 \mu^{0.5} \delta \sigma}$

where $\mu$ is the dynamic viscosity of oil in centipoises, $\delta$ is the slick thickness in $\mathrm{m}, \sigma$ the interface tension of oil-water in dyn $\mathrm{cm}^{-1}$ and $\mathrm{U}$ is the wind velocity in $\mathrm{m}$ $\mathrm{s}^{-1}$.

Model of Huang ${ }^{[3]}$ : He proposed a simplified model to calculate the dispersion according to dispersion constant: $\frac{d V}{d t}=N V_{0} U^{2} t$

where, $\mathrm{N}$ is dispersion constant equal to $2 * 10^{-8}, \mathrm{~V}_{0}$ is the initial volume in $\mathrm{m}^{3}$, $\mathrm{U}$ the wind velocity in $\mathrm{m} \mathrm{s}^{-1}$ and $t$ is the time in $s$.

Model of Audunson ${ }^{[3]}$ : for the dissolution and the vertical dispersion: This model considers that the dissolution and the vertical dispersion can be studied together. For him, this expression represents all the different loss mass of the evaporation:

$\frac{d m}{d t}=\frac{0.4 m U^{2} \exp ^{-0.5 t}}{U_{0}^{2}}$

where, $\mathrm{m}$ is a the oil spill weight in metric tons, $\mathrm{U}$ is the wind velocity in $\mathrm{m} \mathrm{s}^{-1}$ at $10 \mathrm{~m}$ to the sea, $\mathrm{t}$ is the time in days and $\mathrm{U}_{\mathrm{o}}$ is the reference velocity equal to $8.5 \mathrm{~m} \mathrm{~s}^{-1}$.

Emulsification: The emulsification is important in the oil spills because when the water content is increased, the viscosity of petroleum to increase up to two orders of magnitude; the spreading of slick is slow, and if the emulsion is stable all the natural dissipation processes are slow ${ }^{[12]}$. A stable emulsion contains between 50 and $80 \%$ of water, in general, the initial size is increased from 2 to 5 times. The density of petroleum could be increased up to $1.030 \mathrm{~kg} \mathrm{~m}^{-3[13]}$.

In this work an expression which includes algorithms for the evaluation of viscosity and the density was used ${ }^{[2]}$. It is also used by most of the oil spill models, as $\mathrm{ADIOS}^{[14]}$ and $\mathrm{OSCAR}^{[15]}$. This algorithm is expressed in the differential form in function of the initial water content and the water conditions:

$\frac{d F_{w c}}{d t}=K_{w c}\left(U_{10}+1\right)^{2}\left[\frac{1-F_{W C}}{O C_{1}}\right]$

where, $\mathrm{F}_{\mathrm{wc}}$ is the initial water fraction in the oil spill, $\mathrm{K}_{\mathrm{wc}}$ is the emulsification coefficient equal to 2e-6 for light oil ${ }^{[3]}$ or $4.5 \mathrm{e}-6$ for weight oil ${ }^{[16]}, \mathrm{U}$ is the wind velocity in $\mathrm{m} \mathrm{s}^{-1}, \mathrm{OC}_{1}$ is equal to 0.7 for light oil and heaving combustibles ${ }^{[3]}$ or 1.15 for heaving oil ${ }^{[16]}$.

The gasoline, the kerosene and combustibles as diesel do not present emulsification ${ }^{[3]}$.

Evaluation Properties: The viscosity and the density are considered as the most important properties of petroleum spill, they must evaluate to predict the spill behavior when the light components are lost or the water content or the temperature changes.

The Viscosity Changes: When the water content changes: the effect of the water content is calculated by means of the following equation ${ }^{[17]}$. 
$\mu=\mu_{0} \exp \left[\frac{2.5 F_{W C}}{1-0.65 F_{W C}}\right]$

where, $\mu_{\mathrm{o}}$ is the initial oil viscosity and $\mathrm{F}_{\mathrm{wc}}$ is the water content.

When the evaporation changes: The effect of the evaporation is calculated by means of the following equation:

$\mu=\mu_{0} \exp \left(C_{2} * F_{\text {evap }}\right)$

where, $F_{\text {evap }}$ is the evaporated fraction, $C_{2}$ varied between 1 and $10^{[16]}$.

For this model, $\mathrm{C}_{2}$ is equal to 1 for combustibles and light oil , and 10 for other products ${ }^{[3]}$.

When the temperature changes: The variability of viscosity due to its temperature is calculated according to the equation ${ }^{[3]}$ :

$\mu=\mu_{0} \exp \left(8770 T_{K}^{-1}-29.4\right)$

where, $\mathrm{T}_{\mathrm{K}}$, is environmental temperature in ${ }^{\circ} \mathrm{K}$.

Density Changes: The density correction of the emulsification and the evaporation can be calculated by means the following correlation ${ }^{[1]}$ :

$$
\rho=F_{w c} \rho_{w}+\left(1-F_{w c}\right)\left(\rho_{o}+C_{d n} F_{e v p}\right)
$$

where, $F_{w}$ is the water content, $F_{\text {evp }}$ is the evaporated faction, $\rho_{0}$ and $\rho_{\mathrm{w}}$ are densities of oil and water in $\mathrm{kg}$ $\mathrm{m}^{-3}$ and $\mathrm{C}_{\mathrm{dn}}$ is an experimental data obtained in laboratory for each oil. The experimental data of $\mathrm{C}_{\mathrm{dn}}$, was not found. According this, the density correction for emulsificación was only considered:

$$
\rho=F_{w c} \rho_{w}+\left(1-F_{w c}\right) \rho_{o}
$$

\section{METHODS}

Initially, an extensive bibliographical overhaul about the expressions used to predict the included mass transfer processes in a petroleum spill was made. Then, those expressions were classified to determine its applicability; because some expressions require of experimental or field data not available.

The selected expressions accompanied of the correlation for to calculate the spill area and thickness for viscous regime ${ }^{[18]}$ were programmed in Foltran.

The capacity of prediction of the selected expressions was determined by means of the comparison with the field and experimental dates ${ }^{[2,19,20]}$.
Finally, a methodology of evaluation $\left.{ }^{[9,} 22\right]$ was employed with the purpose of determining the degree of adjustment of the model.

\section{RESULTS AND DISCUSSION}

Evaporation: In order to evaluate the evaporation models $^{[5,7,11]}$ an experiment of laboratory ${ }^{[2]}$ was simulated, where the results of the evaporation and composition of the gasoline are known.

In Fig. 2 the comparison results of the evaporation models are observed. The pseudo components models can be used when the crude composition is known; while the analytical models, when the experimental constants of the crude are available. The Center for Environmental Technology of Canada (www.etecntre.org) supplies the experimental data for many oils.

The Mackay and Reed's pseudo component models ${ }^{[3,11]}$ had an adjusted grade equal to 0,96 , and the Findikakis's $\mathrm{s}^{[6]}$ pseudo component model had an adjusted grade equal to 0.986 . While the Fingas's analytical model ${ }^{[7,8]}$ had an adjusted grade equal to 0,989 (Table 1).

Table 1 was elaborated based on the evaluation model proposed by Willmott ${ }^{[22]}$, this does not allow to have clarity about the best models since all the models had an adjustable degree bigger than 0,95 . It is possible to think that the expressions to adapt, however, a simple observation of the curves allows inferences that the Findikakis and Fingas's models are the most appropriate.

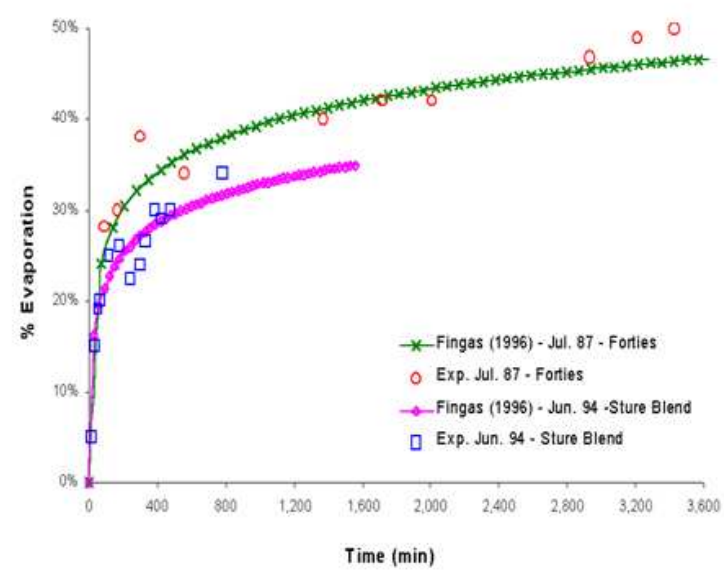

Fig. 2: Gasoline Evaporation: Volume $0.015 \mathrm{~m}^{3}$, Temperature $288^{\circ} \mathrm{K}$, Wind Velocity $6.7 \mathrm{~m} \mathrm{~s}^{-1}$

Table 1: Dissolution Constant

\begin{tabular}{lllll}
\hline Oil type & $\mathrm{C}_{\mathrm{o}}$ & $\mathrm{K}$ & $\mathrm{KC}_{\mathrm{o}}$ & $\propto$ \\
\hline Heaving & 7.88 & 0.002335 & 0.0184 & 0.423 \\
Light & 21.3 & 0.041502 & 0.884 & 2.380 \\
\hline
\end{tabular}


Table 2: Evaluation of the Evaporated Models

\begin{tabular}{lllllll}
\hline Model & Adjustment & $\sqrt{M S E s}$ & $\%$ MSEs & $\sqrt{M S E u}$ & $\%$ MSEu & $\sqrt{M S 1}$ \\
\hline Mackay & 0.960 & $8.4 \times 10^{-2}$ & 43 & $9.6 \times 10^{-2}$ & 57 & $1.3 \times 10^{-1}$ \\
Reed & 0.961 & $1.0 \times 10^{-1}$ & 71 & $6.5 \times 10^{-2}$ & 29 & $1.2 \times 10^{-1}$ \\
Findikakis & 0.986 & $4.6 \times 10^{-2}$ & 38 & $5.9 \times 10^{-2}$ & 62 & $7.4 \times 10^{-2}$ \\
Fingas & 0.989 & $5.5 \times 10^{-2}$ & 80 & $2.8 \times 10^{-2}$ & 20 & $6.2 \times 10^{-2}$ \\
\hline
\end{tabular}

Table 3: Evaluation of Model of Viscosity

\begin{tabular}{lllllll}
\hline Type of crude & Adjustment & $\sqrt{M S E s}$ & $\%$ MSEs & $\sqrt{M S E u}$ & $\%$ MSEu & $\sqrt{M S E}$ \\
\hline Sture Blend & 0.99 & $1.3 \times 10^{-4}$ & 5 & $5.6 \times 10^{-4}$ & 95 & $5.7 \times 10^{-4}$ \\
Troll (day 1) & 0.99 & $3.8 \times 10^{-4}$ & 32 & $5.6 \times 10^{-4}$ & 68 & $6.7 \times 10^{-4}$ \\
Troll (day 2) & 0.98 & $4.5 \times 10^{-5}$ & 80 & $2.3 \times 10^{-5}$ & 20 & $5.1 \times 10^{-5}$ \\
Forties & 0.92 & $1.8 \times 10^{-3}$ & 25 & $3.2 \times 10^{-3}$ & 75 & $3.6 \times 10^{-3}$ \\
\hline
\end{tabular}

Table 4: Change of Properties

\begin{tabular}{lllll}
\hline \multicolumn{2}{l}{ Sture Blend crude } & & & \\
Time (min) & Density $\left(\mathrm{kg} \mathrm{m}^{-3}\right)$ & Viscosity $\left(\mathrm{m}^{2} \mathrm{~s}^{-1}\right)$ & Evaporation (\%) & Water content (\%) \\
0 & 840 & $4.76 \times 10^{-5}$ & 0.0 & 0.0 \\
60 & 878 & $2.37 \times 10^{-4}$ & 19.5 & 24.4 \\
600 & $7.46 \times 10^{-3}$ & 30.45 & 30.4 \\
Troll (fifth day) & 958 & & & \\
Time (min) & Density $\left(\mathrm{kg} \mathrm{m}^{-3}\right)$ & Viscosity $\left(\mathrm{m}^{2} \mathrm{~s}^{-1}\right)$ & Evaporation (\%) & Water content (\%) \\
0 & 893 & $3.36 \times 10^{-5}$ & 0 & 0 \\
60 & 925 & $2.21 \times 10^{-4}$ & 12.2 & 24.4 \\
600 & 971 & $5.12 \times 10^{-3}$ & 18.4 & 74.8 \\
Troll (second day) & Crude & & & \\
Time (min) & Density $\left(\mathrm{kg} \mathrm{m}^{-3}\right)$ & Viscosity $\left(\mathrm{m}^{2} \mathrm{~s}^{-1}\right)$ & Evaporation $(\%)$ & Water content (\%) \\
0 & 893 & $3.36 \times 10^{-5}$ & 0.0 & 0.0 \\
60 & 905 & $1.07 \times 10^{-4}$ & 11.8 & 11.5 \\
450 & 932 & $4.65 \times 10^{-4}$ & 17.6 & 38.0 \\
Forties crude & & & & \\
Time (min) & Density $\left(\mathrm{kg} \mathrm{m}^{-3}\right)$ & Viscosity $\left(\mathrm{m}^{2} \mathrm{~s}^{-1}\right)$ & Evaporation $(\%)$ & Water content (\%) \\
0 & 840 & $1.82 \times 10^{-4}$ & 0.0 & 0.0 \\
60 & 845.7 & $8.12 \times 10^{-4}$ & 23.3 & 3.6 \\
600 & 881.2 & $3.56 \times 10^{-3}$ & 36.5 & 26.1 \\
\hline
\end{tabular}

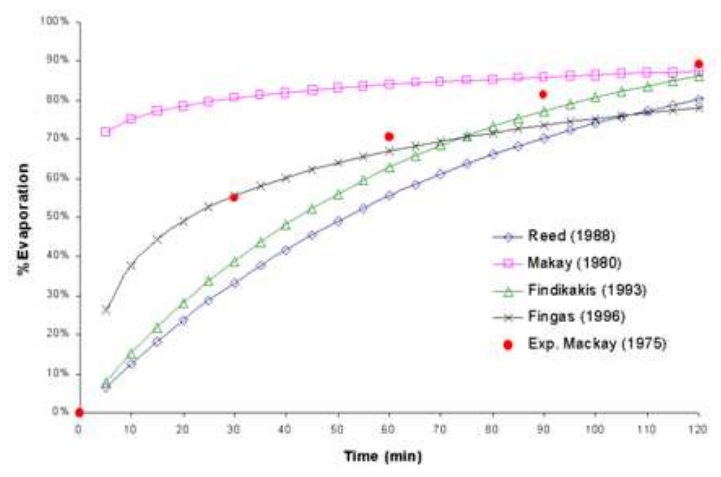

Fig. 3: Evaporative Performance

Based on this investigation, we suggest to use the fingers expression ${ }^{[7,8]}$; since, it had a good adjustment to the experimental data and it is the only one that counts with the experimental information available to be used in the modeling.
According to previous data, the Fingas's expression was compared with the field data of the Norwegian's sea tests were done in June of 1994 with crude Sture Blend and in Julio of 1987 with crude Forties $^{[19,20]}$. In Fig. 3 the comparison of the field data and the simulation area are observed. The crude Forties and the crude Sture Blend are light oils, which have the densities equal to $822,840 \mathrm{~kg} \mathrm{~m}^{-3}$ respectively, and the kinematics viscosities equal to $1.82 \mathrm{e}-4,4.76 \mathrm{e}-5 \mathrm{~m}^{2} \mathrm{~s}^{-1}$, respectively too.

The evaporation begins too fast in the first minutes and then it becomes slow until that is constant due to the liberation of all volatile products, for that reason, when the oil is lighter than other oil the evaporation is faster and greater. For example, in the field data, the Forties's evaporation percentage reached about $38,1 \%$ at $800 \mathrm{~min}$ and the Sture Blend's evaporation percentage reached about $31,8 \%$ at the same time.

Even though the wind speed influences the evaporation, the nature of the crude is more important. 


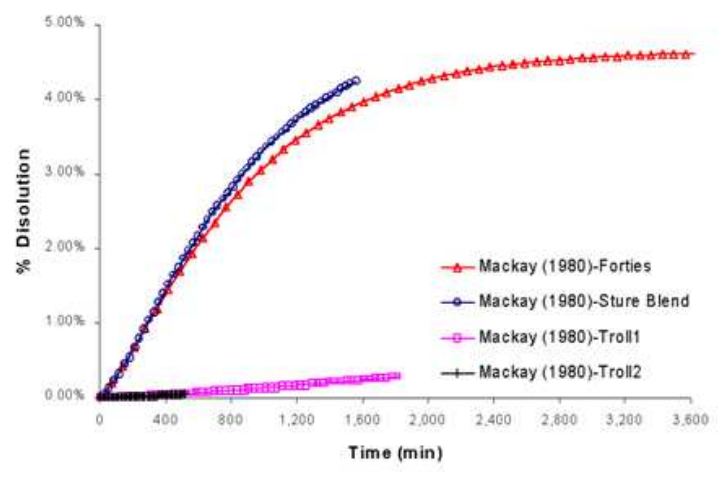

Fig. 4: Behavior of Dissolution

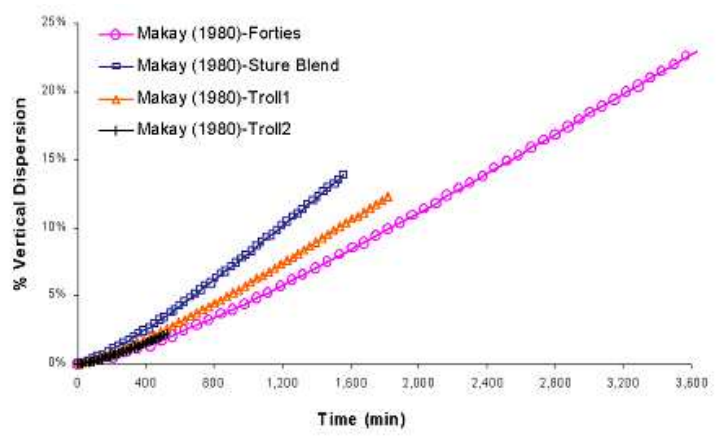

Fig. 5: Behavior or Vertical Dispersion

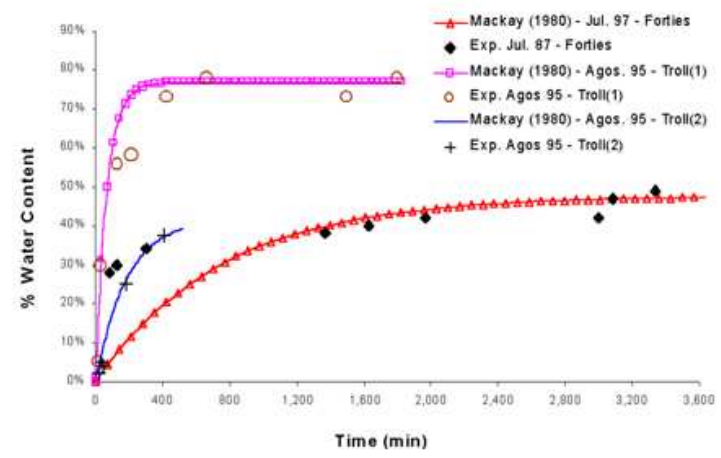

Fig. 6: Behavior of Water Content

This appreciation is valid to the considered field experiments which were made with speeds that vary between 7 and $10 \mathrm{~m} \mathrm{~s}^{-1}$ and nevertheless can be simulated with an independent model of the wind speed, as the implanted in this work ${ }^{[7,8]}$.

Dissolution and Vertical Dispersion: In these phenomena, the field data was not found that allowed to compare the output; however, according to the

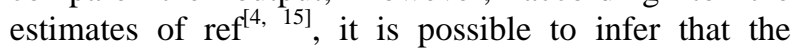
outputs are adequate. The dissolution represents a percentage less than $5 \%$ and the vertical dispersion is approximately equal to $40 \%$ or less on the first days in normal conditions (Fig. 4 and 5). For the dissolution and the vertical dispersion the four field experiments were modeled ${ }^{[4,15]}$.

According to Fig. 4 the dissolution is large for light oils (Forties and Sture Blend crudes) that increase quickly until 1,000 min and then becomes constant due to the loss of light products. After the first day the dissolution is not important.

According to Fig. 5 the vertical dispersion is larger for the heavier oils. For example, for the Forties and Sture Blend oils which have a density between 822 and $840 \mathrm{~kg} \mathrm{~m}^{-3}$, respectively, at $1,600 \mathrm{~min}$ the vertical dispersion is equal to $8 \%$ and $14 \%$, respectively.

On the other hand, it is possible to identify a dependence between the vertical dispersion and the wind velocity. For example in the simulated experiments with the Troll oil (day one and two), carried out with the wind speeds of 9 and $6 \mathrm{~m} \mathrm{~s}^{-1}$, respectively it is observed that the vertical dispersion is larger for the first day, when the wind speed was larger. At $450 \mathrm{~min}$, the vertical dispersion of the Troll oil in the first day was equal to $2.4 \%$, while for the second day was equal to $2.1 \%$

According to the constants of emulsification, for the case of the Forties, light oil was utilized $\mathrm{K}_{\mathrm{A}}=5 \mathrm{e}-6$ and $\mathrm{C}_{1}=2.1$, and for the Troll, heavy oil was utilized $\mathrm{K}_{\mathrm{A}}=5 \mathrm{e}-5 \quad \mathrm{C}_{1}=1.32$. These values are within the proposed range ${ }^{[3,16]}$, which are based on experimental correlations.

The comparisons allow concluding that the heavy oils have a larger tendency to emulsification. In addition, for the Troll's case the content of water is proportional to the density and the wind speed.

\section{Change of Properties:}

Viscosity: The viscosity correction depends of the three important factors: the water content of the oil, the evaporated fraction and the temperature. When the temperature is constant according to the field data ${ }^{[4,15]}$, it is only necessary to carry out corrections for the water content and the evaporation (Fig. 7).

The experimental data of the viscosity show a great variation through the time. For example: for the Forties oil, the viscosity, increases about 90 times; for the Troll oil (day one) 210 times; for the Troll oil (day two) 20 times and for the Sture Blend oil, 226 times. Each of the experiments had a different duration $(3,600 \mathrm{~min}$, Forties case; 1,600 min, Sture case; 1,800 min, Troll case, day one; and $450 \mathrm{~min}$, Troll case, day two).

If we consider the same time for the four cases (400 $\mathrm{min}$ ), the variation of the viscosity are about 14 times for the Forties oil, 93 times for the Sture oil, 113 times for the Troll oil on the first day, and 17 times for the Troll oil on the second day. This allows to infer that for the analyzed experiments the viscosity change is larger when the speed of the wind is larger as the experiments with Troll oil first and second day. In addition, the viscosity change is larger for the light oil, as in the case of the Sture Blend oil (Table 3). 


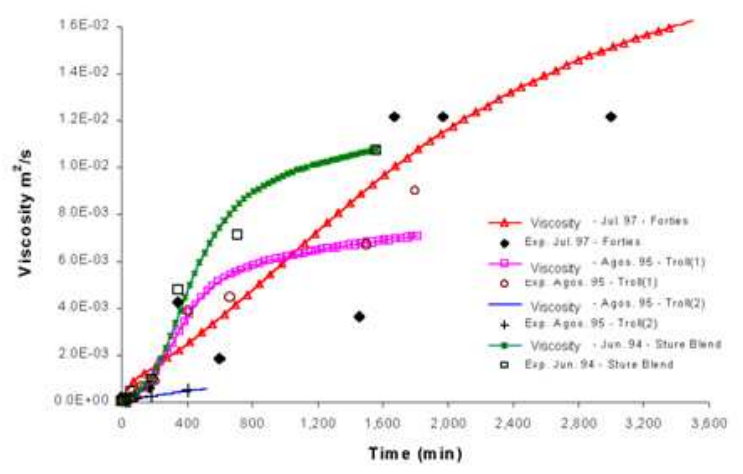

Fig. 7: Behavior of the Viscosity

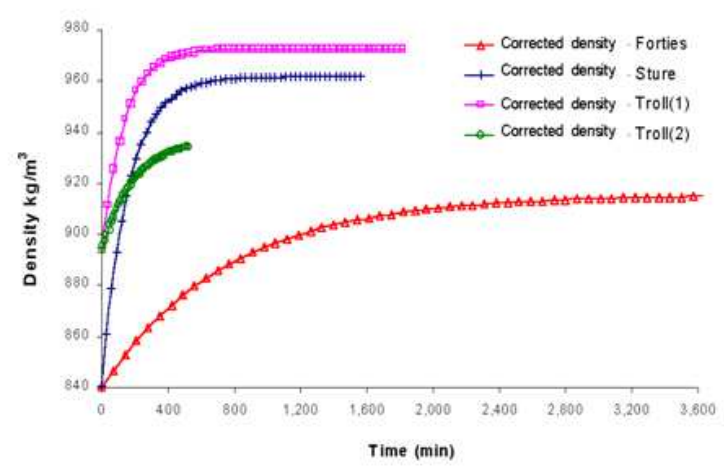

Fig. 8: Behavior of Density

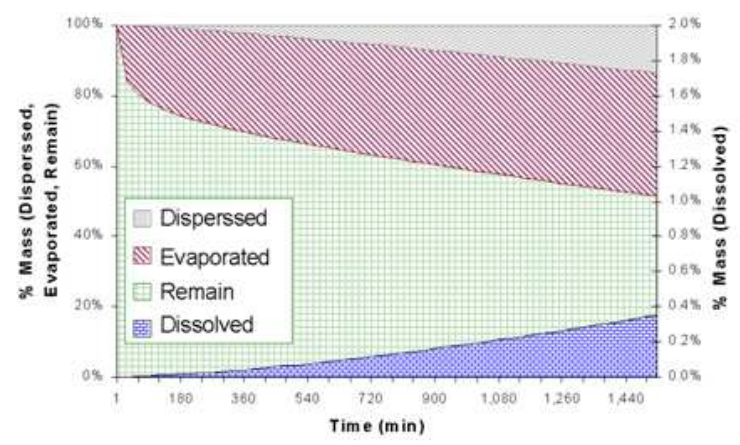

Fig. 9: Integrated Process for Forties Crude

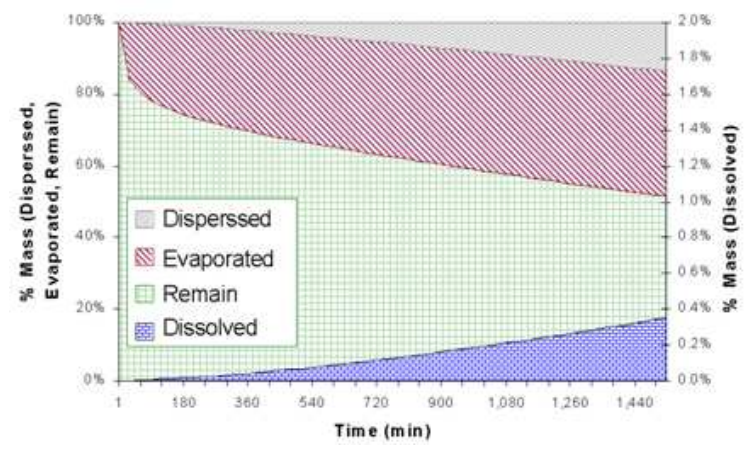

Fig. 10: Integrated Process for Sture Blend Crude
In order to simulate the field tests, several values of the correction coefficient of the viscosity by evaporation were used: 6 for the Forties crude, 4.5 for the Sture Blend crude and 8.5 for the Troll crude. According to Reed et al. ${ }^{[3]}$, the coefficient of correction of the viscosity by evaporation could vary from 1 to 10 from the light crude to the heavy crude.

Density: The density changes depend on heavy the water content and the evaporation of the lightest hydrocarbons; however, in the results of Fig. 8, the variation due to the water content is plotted, since the evaporation correction requires the experimental constant. This work does not have the experimental data in order to compare the output. It is possible to appreciate a direct dependence between the water content and the property changes (Table 4 ).

Integrated process: In Fig. 9 and 10 the integrated behavior of the evaporation, the dissolution, and the vertical dispersion processes is illustrated. In this are corroborating that: for heavy petroleum the vertical dispersion begins earlier than in the light petroleum, evaporation is the first process that is acting in a petroleum spill, vertical dispersion begins to be imported at a later time than the evaporation and dissolution, evaporation and vertical dispersion is larger when the wind speed is larger, dissolution is larger when the spill area is bigger, and each process reaches its maximal average when its effect is negligible.

\section{CONCLUSION}

A recent model of evaporation ${ }^{[7,8]}$ was analyzed which requires the knowledge of experimental data for each oil, these are given by the Center of Environmental Technology from Canada (www.etecentre.com). This model had an adjustment equal to 0.98 with the used experimental data. For this reason, we concluded that the best evaporation model is that of Fingas.

The experimental data of gasoline evaporation were compared ${ }^{[2]}$ with the results obtained by the methods of pseudo components ${ }^{[3,5,11]}$, that are based on the theory of the proposed mass transfer coefficient ${ }^{[8]}$. Adjustments equal to $0.96,0.961$ and 0.986 were obtained respectively. In this case, was checked that when it is possible have the oil characterization these formulations could be used.

The dissolution model ${ }^{[11]}$, based on the mass transfer superficial phenomena, which employs a characteristic coefficient for several oil groups, based on the API graveness was tested. The modified version ${ }^{[5]}$ offers the coefficient than adjusts better with experimental data reported ${ }^{[10]}$. For this reason, this model is the most appropriate for dissolution.

Several authors ${ }^{[3,11,16]}$ have modeled the vertical dispersion process. All the models can be used, however, the model ${ }^{[11]}$ is the best, because this model 
involves a larger number of considered parameters and that have been used in the majority of the reported model $^{[3,6,16,20]}$.

The models employed to evaluate the viscosity increase by the evaporation and emulsificación ${ }^{[3,}$ 11] represent the experimental behavior. In this case, an adjustment equals to 0.92. is obtained The model used in order to determine the variation of the viscosity is better.

Using values between 6 and 10 for the emulsification coefficient $^{[3]}$ an adjustment equal to 0.98 with experiment data ${ }^{[19]}$ was obtained. For this reason, it is not necessary to consider a range from 1 to 10 as it was proposed in ref $^{[3]}$.

\section{ACKNOWLEDGMENT}

Particular thanks are to the Institute of Engineering of the Autonomous University from Mexico support to carry out this investigation of petroleum spills.

\section{REFERENCES}

1. Stiver, W. and D. Mackay, 1984. Evaporation rate of spills of hydrocarbons and petroleum mixtures. Environ. Sci. Technol., 18: 834-840.

2. Mackay, D. and R. Matsugu, 1975. Evaporation rates of liquid hydrocarbon spills on land and water. The Canadian J. Chem. Engg., 51: 434-439.

3. Reed, M., T. Kana and E. Gundlach, 1988. Testing and verification of a spill surf zone mass transport model. Alaska, OCS Region, Minerals Management Service, 949 East $36^{\text {th }}$ Avenue, Room 110 anchorages, ak 99508-4302.

4. Spaulding, M., 1988. A state-of-the-art review of oil spill trajectory and fate modeling. Oil and Chem. Poll., 4:39-55.

5. Shen, H. and P. Yapa, 1988. Oil slick transport in rivers. J. Hydraulic Engg., 114-5: 529-543.

6. Findikakis, A. and Law A. Papadimitrakis, 1998. Assessment of the Risk of Shore Contamination by Offshore Oil Spills, Model Formulation Oil and Hydrocarbon Spills Modeling, Analysis and Control, Computational Mechanics Public as Hurts, pp: 209-220.

7. Fingas, M., 1996. The evaporation of oil spills: Prediction of equations using distillation data. Spill Sci. Technol. Bull., 3-4: 191-192.

8. Fingas, M., 1997. The evaporation of oil spills: prediction of equations using distillation data. Proceedings of the $20^{\text {th }}$ Arctic and Marine Oil Spill Program (AMOP) Technical Seminar, Environment Canada, pp: 1-20.
9. ITOPF, 1999. Fate of marine oil spills. International Tanker Owners Pollution Federation, www.itopf.com/fate.html

10. Cohen, Y., D. Mackay and W. Shiu, 1980. Mass transfer rates between oil slicks and water. The Canadian J. Chem. Engg., 58: 569-575.

11. Mackay, D., I. Buist, Mascarenhas and S. Paterson, 1980. Oil spill processes and models. Environment Canada Report EE-8.

12. NOAA, 1995. R. Overstreet and J. Galt, Physical Processes Affecting the Movement and Spreading of Oils in Inland Waters, National Oceanic and Atmospheric Administration, pp: 1-45, Seattle. Washington.

13. Reed, M., O. Johansen, P. Brandvik, P. Daling, A. Lewis, R. Fiocco, D. Mackay and R. R. Prentki, 1999. Oil spill modelling towards the close of the 20th century: Overview of the state of the art. Spill Sci. Technol., 5-1: 3-16.

14. ASCE, 1996. State-of-the-art review of modeling transport and fate of oil spills. American Society of Civil Engineers, J. Hydraulic Engig., 122- 11: 594609.

15. Muharemi, R., R. Buffagni, M. Puletti, P. Daling and M. Reed, 2000. Application of the oil spill contingency and response (OSCAR 2000) model to on offshore field in the Adriatic sea, International Marine Environmental Conference 2000 on numerical and physical modeling of environmental processes, Atenas, Grecia.

16. Rasmussen, D., 1985, Oil spill modeling-a tool for cleanup operations, Proceedings of the 1985 Oil Spill Conference, American Petroleum Institute, Washington, pp: 243-249.

17. Perry, C., 1992, Manual Del Ingeniero Químico, Publisher of McGraw-Hill, México.

18. Fay, J., 1971. Physical processes in the spread of oil on the water surface. American Petroleum Institute, Proc. Joint Conf. To Preventing and Control of Oil Spills, pp: 463-467.

19. Dalling, P.S. and T. Strom, 1999. Weathering of oil at sea: Model/Field Data Comparisons. Spill Sci. Technol. Bull., 5-1: 63-74.

20. Zhi-Wei, L., Z. Shu-Shen and C. Mead, 2000. Modeling of the behavior of marine oil spills: Applications based on random walk techniques. J. Environ. Sci., 12-1: 1-6.

21. Garcia, R., 1998. Some recommendations for testing oil spill computer models, oil and hydrocarbon spills. Modeling, Analysis and Control, pp: 97-105.

22. Willmott, C., 1981. On the validation of models. Physical Geography, 2: 184-194. c 